\title{
The role of musical experience in the lives of Williams syndrome individuals
}

\author{
EWIE ERASMUS
}

\begin{abstract}
The purpose of this literature study is to better understand the musical experiences of those diagnosed with Williams syndrome. The problem of this study is defined by the lack of qualitative studies done on the musical experiences of Williams syndrome individuals. Research done on music and Williams syndrome emphasise the intense affinity that those diagnosed show towards music listening and music making, yet very few qualitative studies have been done on the importance of musical experience in the everyday lives of those diagnosed with Williams syndrome. The study at hand will provide insight into the lives of individuals with Williams syndrome, while focussing on the importance of musical experience, raising the awareness of caretakers, educators, therapists and researchers. This qualitative study was aided by Atlas.ti 7 computer software which assisted me in document analysis through a grounded theory approach. For the data analysis process, significant statements were identified and then coded. These codes were then sorted to reveal categories and main themes. Literature revealed that music could in fact play an important role in the lives of those living with Williams syndrome. Musical experience does not only have a positive influence on a single aspect of the lives of Williams syndrome individuals, it has an impact on their lives in general, influencing their overall well-being.
\end{abstract}

Keywords. Williams syndrome, literature review, qualitative, phenomenology

\section{Introduction}

This study was inspired by my experiences with a Williams syndrome child which made me aware that the child has an intense love of and need for music in everyday life. The unusual grasp of and attentiveness to music drew my attention to the possible importance of musical experience in the lives of those diagnosed with Williams syndrome.

The problem of this study is defined by the lack of qualitative empirical studies done on the musical experiences of Williams syndrome individuals. Research done on Williams syndrome and music emphasise the intense affinity that those diagnosed show towards music listening and music making. Music is also one of the areas in which Williams syndrome individuals appear to excel. It seems odd then, that very few qualitative studies have been done on the importance of music in the everyday lives of those diagnosed with Williams syndrome. This review synthesises, from the existing literature, the possible role of musical experience in the lives of individuals diagnosed with Williams syndrome.

Ewie Erasmus is a MMus student of North-West University, Potchefstroom-campus (niche entity Musical Arts in South Africa: Resources and Applications). Her research interests lie in the fields of lived musical experiences and music education for those with special needs. ewievdm@gmail.com 
There are many quantitative studies focussing on the neuropsychology and cognitive profile of those diagnosed with Williams syndrome. Furthermore, extensive research has been done on the language and musical abilities commonly associated with the syndrome, emphasising links and dissociations between the neuropsychology, cognitive profile, language and musical strengths in Williams syndrome. Not many researchers, however, draw focus to the meaning those diagnosed with Williams syndrome ascribe to musical experience or the importance thereof in Williams syndrome individuals' lives. And it is this aspect that interests me most.

The literature review at hand shall provide a summarised view into a neurodevelopmental syndrome which has attracted the attention of many renowned researchers. This study will thus summarise existing research on Williams syndrome from a holistic point of view while trying to understand the world from the perspective of those often not listened to (Merriam, 2009:6), giving voice (Creswell, 2013:44) to Williams syndrome individuals.

This summary will prove helpful to researchers who aim to embark in qualitative studies on Williams syndrome, while drawing focus to the importance of music in the lives of Williams syndrome individuals from a special needs music education and psychological perspective. As this literature review will draw conclusions on the musical experiences of Williams syndrome individuals, it holds value for researchers undertaking phenomenological studies. The goal of research on Williams syndrome is to further the understanding of the syndrome, raising the awareness of caregivers, educators, researchers and therapists about the impairments and strengths associated with the syndrome.

For this article, the purpose statement and main research question will first be given, after which the research design, followed shall be described. The literature review which will discuss existing research on Williams syndrome, while focussing on defining Williams syndrome, cognitive phenotype, language, sociability, auditory abnormalities and music. In the end, this study aims to highlight certain aspects contributing to the possible importance of musical experience in the lives of individuals living with Williams syndrome.

The purpose of this literature study is to understand the musical experiences of those diagnosed with Williams syndrome.

\section{Methodology}

This qualitative study was aided by Atlas.ti 7 computer software, which assisted me with document analysis through a grounded theory approach. The documents analysed were initially gathered through a process of collecting any and all literature on Williams syndrome and more specifically Williams syndrome and music. The data collection and analysis processes were interconnected from the onset of the study, seeing that documents that would be included and excluded for this study was immediately identified. This process was guided by the purpose statement and research questions. The documents included in this study mainly include accredited articles. As soon as the documents that would be used for the study at hand were identified, the process of in depth data analysis started. Firstly, through open coding, significant statements (quotes) were identified, which would aid the understanding of musical experiences in the lives of Williams syndrome individuals. Secondly, codes were assigned to each of the quotes identified. These codes were then organised into categories, revealing the main themes. When data saturation was reached, the final organisation process was started in order to write up the findings. 


\section{Literature review}

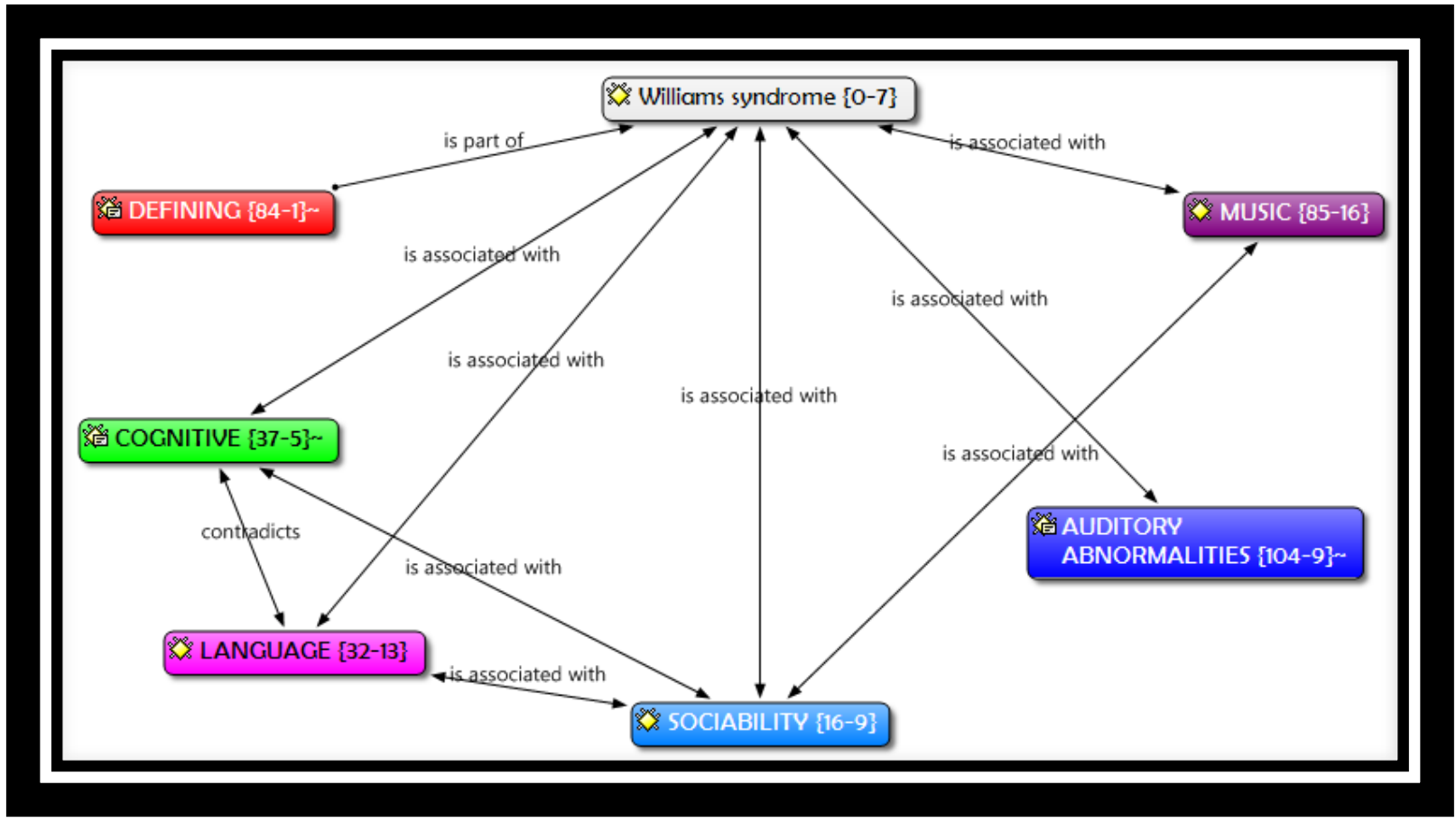

Figure 1: The structure of this article also displaying the density of all the identified themes and how grounded these themes are in the literature

In order to make sense of the importance of musical experience in the lives of Williams syndrome individuals it is necessary to first define the syndrome by reviewing the general literature. The syndrome shall be defined in terms of genetic makeup, neuropsychological profile, cognitive phenotype, sociability, auditory abnormalities, language and musical abilities associated with the syndrome. The possible importance of music in the lives of those diagnosed with Williams syndrome will also be discussed.

\section{Defining Williams syndrome}

Williams Syndrome is a rare neurogenetic developmental disorder (Levitin, 2005:1) which presents itself in approximately one out of every 20,000 live births. The syndrome was first discovered by British cardiologist, Dr. Williams and his colleagues, in 1961 (Levitin \& Bellugi, 1998:358). Williams Syndrome characteristics can be divided into six main categories which include physical aspects, medical conditions, neuropsychological profile, cognitive abilities, language and sociability. This review focuses on cognitive abilities, language and sociability.

Williams Syndrome individuals can easily be identified by certain physical aspects which include a slender build, broad forehead and a sunken nasal bridge. They also tend to have blue, puffy eyes. Furthermore, individuals living with the syndrome can be identified by their wide mouth, long upper lip, prominent lower lip, small widely spaced teeth and small chin (Levitin \& Bellugi, 1998:358). 
Those diagnosed with Williams syndrome tend to suffer from certain medical conditions which include cardiovascular abnormalities resulting in a narrowed aorta and scoliosis. They also often have renal and digestive problems and perforated intestines. Hypercalcemia and curvature of the spine are also among the medical conditions commonly associated with Williams syndrome (Levitin \& Bellugi, 1998:358-359).

Williams syndrome is associated with an abnormal psychological profile which has an effect on the behaviour of those diagnosed. Individuals diagnosed, have IQ's ranging between 40 and 100 with a mean of 60 (Levitin \& Bellugi, 1998:358; Du Four, 2008:2). They also show impaired spatial, quantitative and reasoning abilities (Levitin, 2005:9). These individuals do, however, display spared abilities in the domains of facial recognition, language, sociability and music (Du Four, 2008:6; Levitin, 2005:9; Levitin et al., 2003:7; Martens et al., 2010:6).

\section{Cognitive phenotype}

Williams syndrome is associated with an unusual cognitive profile which features mental impairment (Bellugi et al., 1994:32) and certain dissociations (Bellugi et al., 2007:8). The cognitive profile can also be characterised by peaks and valleys of abilities within and across certain cognitive domains (Bellugi et al., 1994:22; Bellugi et al., 2000:90). Williams syndrome individuals tend to show unusually good facial processing abilities, especially when considering that they fail Piagetian tests of conservation skills for numbers, weight and substance (Bellugi et al., 1994:36). Furthermore, individuals living with the syndrome often have difficulty with coordination (Bellugi et al., 2000:105) and mathematics and its application in everyday life (Bellugi et al., 2000:95). Those diagnosed also generally have poor motor skills which lead to difficulty tying shoes and poor eye-hand coordination overall (Levitin \& Bellugi, 1998:74).

The cognitive profile of people diagnosed with Williams syndrome include dissociations between general cognitive functioning, i.e. visual-spatial processing, facial recognition and language abilities (Bellugi et al., 1994:92; Bellugi et al., 2000:75; Pani et al., 1999:12; Du Four, 2008:3). Studies have found evidence for the separate functioning of language, spatial abilities and facial processing in human behaviour (Bellugi et al., 2000:82).

\subsection{Visual-spatial development}

The visual-spatial functioning of those with Williams syndrome is severely impaired, resulting in individuals having difficulty with simple tests of spatial perception (Bellugi et al., 1994:63). This impairment can also be observed in narratives, where individuals diagnosed, tend to misuse spatial prepositions. This becomes clear in a study done by Bellugi et al. (2000:125) when a subject stated that "The dog has the jar in his face" when presented with a picture of a dog with his head in a jar. Their findings are suggestive of problems in language when used to describe spatial relations.

Other studies that have been done on the drawing skills of Williams syndrome individuals highlight their visual-spatial impairment, presenting drawings with poor cohesion and a lack of organisation (Bellugi et al., 2000:115). Individuals diagnosed tend to talk their way through their unorganised drawings. Thus it becomes clear that children with Williams syndrome struggle to focus on the bigger picture (Levitin \& Bellugi, 1998:361). Instead, they focus on every detail, as if, removed from the whole. This is demonstrated in a study done by Levitin and Bellugi (1998:362) as seen in the example in figure 2 which shows that these children focus on detail rather than context. 


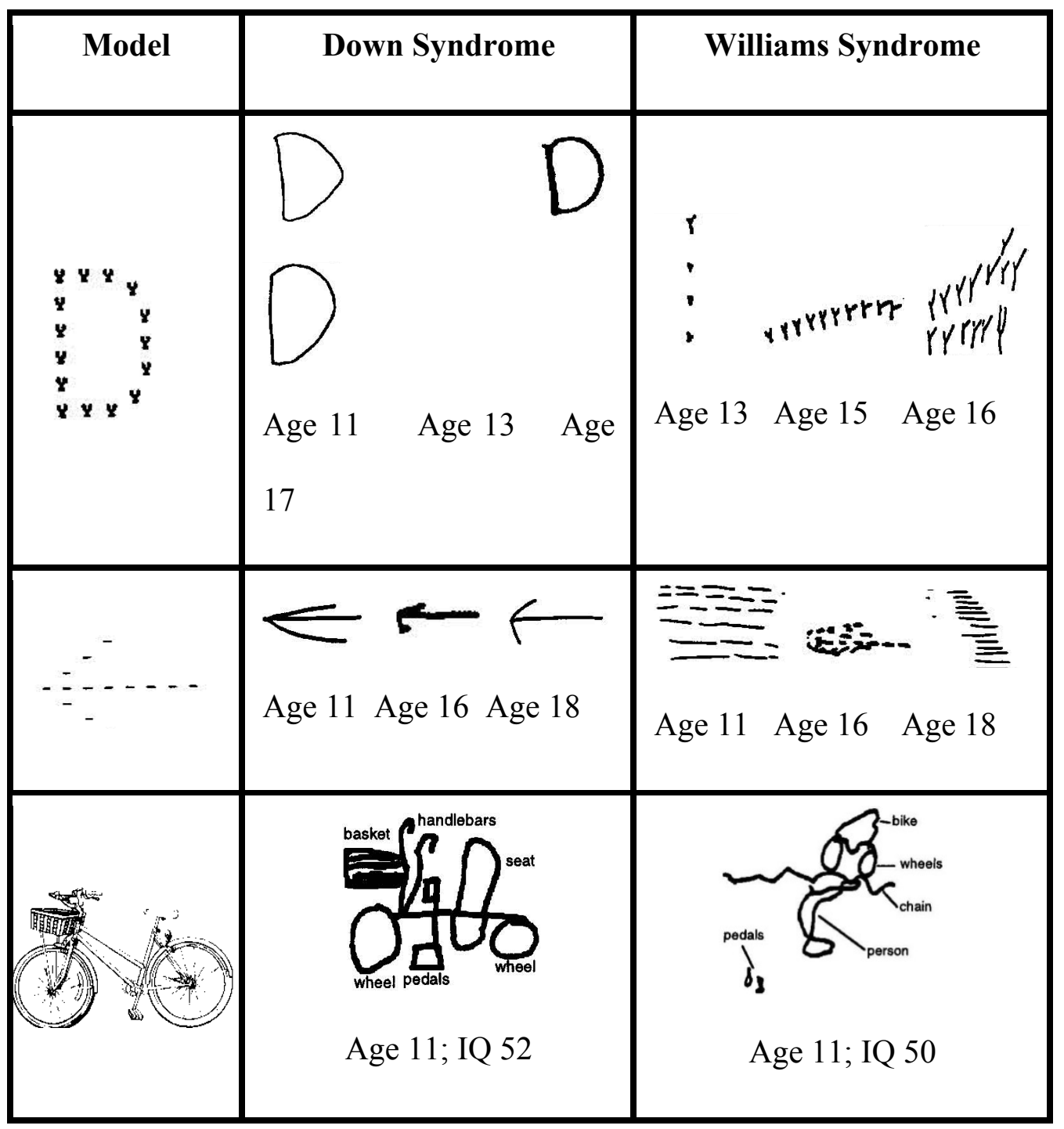

Figure 2: (Levitin \& Bellugi, 1998:362)

Despite having these difficulties with visual-spatial processing, those diagnosed with Williams syndrome display a good ability to discriminate between unfamiliar faces. This also holds true for the identification of objects that are shown from unusual perspectives (Bellugi et al., 1994:72; Bellugi et al., 2000:76), revealing certain peaks and valleys within the visualspatial cognition of Williams syndrome individuals (Bellugi et al., 2000:70).

People diagnosed with Williams syndrome tend to easily find their way around new buildings and easily place objects in containers. The main problem with visual-spatial cognition thus seems to be spatial construction as described by local and global processing (Pani et al., 1999:7). Those with Williams syndrome struggle to see objects as global configurations and do not, for example, see a flock of birds as flying in a V-shape, but rather see each bird individually. They also tend to have difficulty tying their shoes, drawing and building models (Pani et al., 1999:14). 


\section{Language abilities}

Researchers suggest that the mastery of the concept of conservation, which embodies ideas of reversibility and transitivity, is a prerequisite for understanding passive sentences in language. The visual-spatial profile of Williams syndrome contradicts this argument, seeing that these individuals fail tests for conservation, but show well developed skills in language (Bellugi et al., 1994:76).

People diagnosed with Williams syndrome pose unusually well-developed narrative and linguistic capabilities resulting in spontaneous fluent speech, good phonology and good vocabulary (Levitin \& Bellugi, 2006:2). Despite the fact that individuals diagnosed tend to use unusual words when engaging in conversation, and seem unable to understand the world, Williams syndrome individuals continually use affective prosody in conversations and narratives (Bellugi et al. $(2007: 100 ; 1994: 78)$. This shows that they are not totally incapable of understanding the world, as affective prosody relies on knowledge of cultural expectations and affective astuteness. Grammar, on the other hand, is less likely to depend on nonlinguistic ability. The language profile as seen in individuals diagnosed with Williams syndrome suggest that certain linguistic skills may become independent form general cognitive ability (Bellugi et al., 1994:79-95).

Bellugi et al. (1994:98) emphasise that Williams syndrome individuals show evidence of semantic deviation and preservation. This could support the notion that semantic organisation may depend on general cognition (Levitin \& Bellugi, 1998:44). Most researchers however, argue that the structural aspects of language are a relative strength in Williams syndrome. In a study done by Bellugi et al. (2000:58) they state that, rather than saying that the syndrome represents dissociation between language and general cognition, one could argue that the preserved language skills enable Williams syndrome individuals to reach levels of performance otherwise deemed impossible.

Individuals with Williams syndrome generally provide well-structured narratives. In their narratives, they establish direction, introduce time and characters and the characters' states of mind and behaviours. They also tell stories with clear problems that are resolved in the time the story is being told. The stories that Williams syndrome individuals tell, further present good grammatical skills and the use of narrative enrichment devices which contribute to the drama of the story (Bellugi et al., 1994:49). Williams syndrome individuals perform well in tasks where they are asked to tell a story from a drawing. They tend to draw on their imagination to tell coherent stories filled with paralinguistic devices such as whispering and exaggeration often using phrases like "lo-and-behold", "all-of-a-sudden", "guess what happened next!", to grab the attention of their audience (Levitin \& Bellugi, 1998:28).

According to Levitin and Bellugi (1998:359), the exceptional language development of people who are diagnosed with Williams Syndrome facilitates their sociability (Bellugi et al., 2007:100). This is an important quality to keep in mind when studying the musical experiences of Williams Syndrome children since they perform optimally in social settings.

\section{Sociability}

Williams syndrome is characterised by hyper-sociability which includes overfriendliness and a heightened approachability toward others, especially strangers (Bellugi et al., 2007:11). 
Because of this hyper-sociability, these individuals also present an incapability to discriminate between positive and negative unfamiliar faces (Bellugi et al., 2007:19).

The hyper-sociability associated with Williams syndrome was proven in a study conducted by Levitin (2004:226) which shows that Williams Syndrome children have higher levels of sociability than typically developing children of the same age. The study was done on the rhythmic capabilities of children with Williams syndrome as compared to other special needs children. Williams Syndrome children showed fewer capabilities in rhythmic tasks than other children when using recorded music to conduct the test, but their scores improved immensely when someone played the material on an instrument during the test. In another study, done by Bellugi et al. (2007:21), researchers set out to collect data on the emotions elicited by Williams syndrome children when a toy was placed behind a barrier before the child. They could however, not collect any data seeing that the children focussed on the experimenter's face, rather than on the toy. These two studies emphasise the need Williams syndrome individuals have for and their love of social interaction. Another prominent characteristic exhibited by people diagnosed with Williams syndrome is auditory abnormalities in the perception of everyday sounds.

\section{Auditory abnormalities}

Williams Syndrome individuals tend to be overly sensitive to loud noises and timbre. This unusual sensitivity to certain environmental sounds is one of the key psychophysical features associated with Williams Syndrome (Bellugi et al., 1994:6; Levitin, 2005:18). These sensitivities are manifested in specific ways which include an awareness of sounds before others (true hyperacusis), an aversion to sounds not usually considered aversive in normal populations (auditory allodynia), a fascination with certain sounds (auditory fascinations) and a lowered hearing threshold for loud sounds (odynacusis) (Levitin et al., 2005:70). Auditory fascinations are usually presented together with a type of auditory acuity which allows Williams syndrome individuals to differentiate between different vacuum cleaner brands or lawnmowers (Salk Institute, 2006:2). This often leads to some individuals living with the syndrome being drawn to sounds others cannot stand. These concepts of aversion, awareness and attraction could characterise the auditory anomalies observed in Williams syndrome and may help to describe the phenotype associated with the syndrome. According to Gothelf et al. (2006:4) the onset of these symptoms start before one year of age and tend to decrease during adolescence.

Research has found that the Williams syndrome group seem to have considerably higher ratings of auditory abnormalities than normal controls (Du Four, 2008:22; Levitin, 2005:27; Levitin et al., 2005:3). It is important, however, to note that the term hyperacusis has long been used to describe any type of auditory abnormality, when it in fact only refers to an abnormal sensitivity to sound. This means that the term only refers to the ability to detect soft sounds before others or that others normally cannot detect (Levitin, 2005:22; Levitin et al., 2005:16).

\subsection{True hyperacusis}

Hyperacusis refers to an unusual sensitivity to and interest in sound. The sensitivity to sound presented in Williams syndrome are usually related to specific timbres (Levitin \& Bellugi, 2006:23). These individuals also seem to have something related to perfect pitch and are able to code, recall and label stimuli along the pitch continuum. They notice small variations in 
timbre with finer distinction than others (Levitin \& Bellugi, 1998:117). This ability to classify objects based on timbre suggests a highly developed recognition memory, in this regard sometimes described as 'hypertimbria'.

Levitin et al. (2005:45), reported a girl who was sensitive to the sound of a particular vacuum cleaner but not to others. She could hear the specific vacuum houses away and described the sound as follows: "The sound gets inside my head and reverberates". True hyperacusis is associated with auditory fascinations in the sense that hyperacusis can also refer to an abnormally strong affective response to certain categories of sound (Levitin \& Bellugi, 2006:36). These responses are typically linked to fascinations with these sounds.

\subsection{Auditory allodynia}

Auditory allodynia is also referred to as phonophobia - an aversion to or fear of sounds not normally found aversive (Levitin, 2005:45). In response to these sounds Williams syndrome children would typically display feelings of fear, cover their ears, cry or leave the room (Gothelf et al., 2006:5). Parents of Williams syndrome children reported that the reactions of their children to these sounds made it clear that they did not necessarily find these sounds too loud, but that they were truly frightened by them (Levitin et al., 2005:31).

These frightening sounds can be classified in different categories which include broad-band continuous sounds (e.g. blender, vacuum, lawnmower, airplane, cheering, crowd, engine), broad-band percussive sounds (sudden onset sounds like fireworks, balloons popping, pulsed fire alarms, thunder, door slam), narrow-band continuous sounds (e.g. dentist equipment, air brakes, power saw, power drill) and human/animal sounds (e.g. babies crying, screaming, yelling, dog barking, operatic singing, frequency sweeping sirens, coughing, sneezing) (Levitin et al., 2005:36-38).

The fear of certain sounds could lead to Williams syndrome individuals avoiding birthday parties, because of a fear of the noise of bursting balloons. Gothelf et al. (2006:6) refer to a 16 year old girl who described this kind of suffering, stating that "When I hear the sound of an electric drill, I feel as if it is drilling into my body". Levitin (2005:28) found that Williams syndrome children often outgrow their fear of certain sounds (auditory allodynia) and that those sounds then become the objects of their intense fascination.

\subsection{Auditory fascinations}

According to Levitin et al. (2003:14), one would find numerous anecdotes telling of Williams syndrome children who would sit entranced by music or the sound of leaf blowers, automobile engines or other noises for hours on end. They would be able to name the make and models of vacuum cleaners and engines based only on the acoustic information (Levitin et al., 2005:65). They appear to derive as much pleasure and fascination from these everyday sounds as from music. Studies done by Levitin (2005:29) found many stories about Williams syndrome children and their auditory fascinations which include the story of a Williams syndrome child who had a collection of vacuum cleaners and yet asked for a new one every Christmas. There are also reports of these children who would describe the sound of lawnmowers or vacuum cleaners as "the most beautiful sound ever". 


\subsection{Odynacusis}

People with Williams syndrome often display inappropriate responses to and complaints of uncomfortable loudness levels to sounds that are not threatening or uncomfortably loud to others. This reaction to sound is characterised as odynacusis (Levitin \& Bellugi, 2006:35). It is important to note that odynacusis does not refer to sound that evoke fear in those with Williams syndrome, but only to sounds perceived as uncomfortably loud.

\section{WS and music}

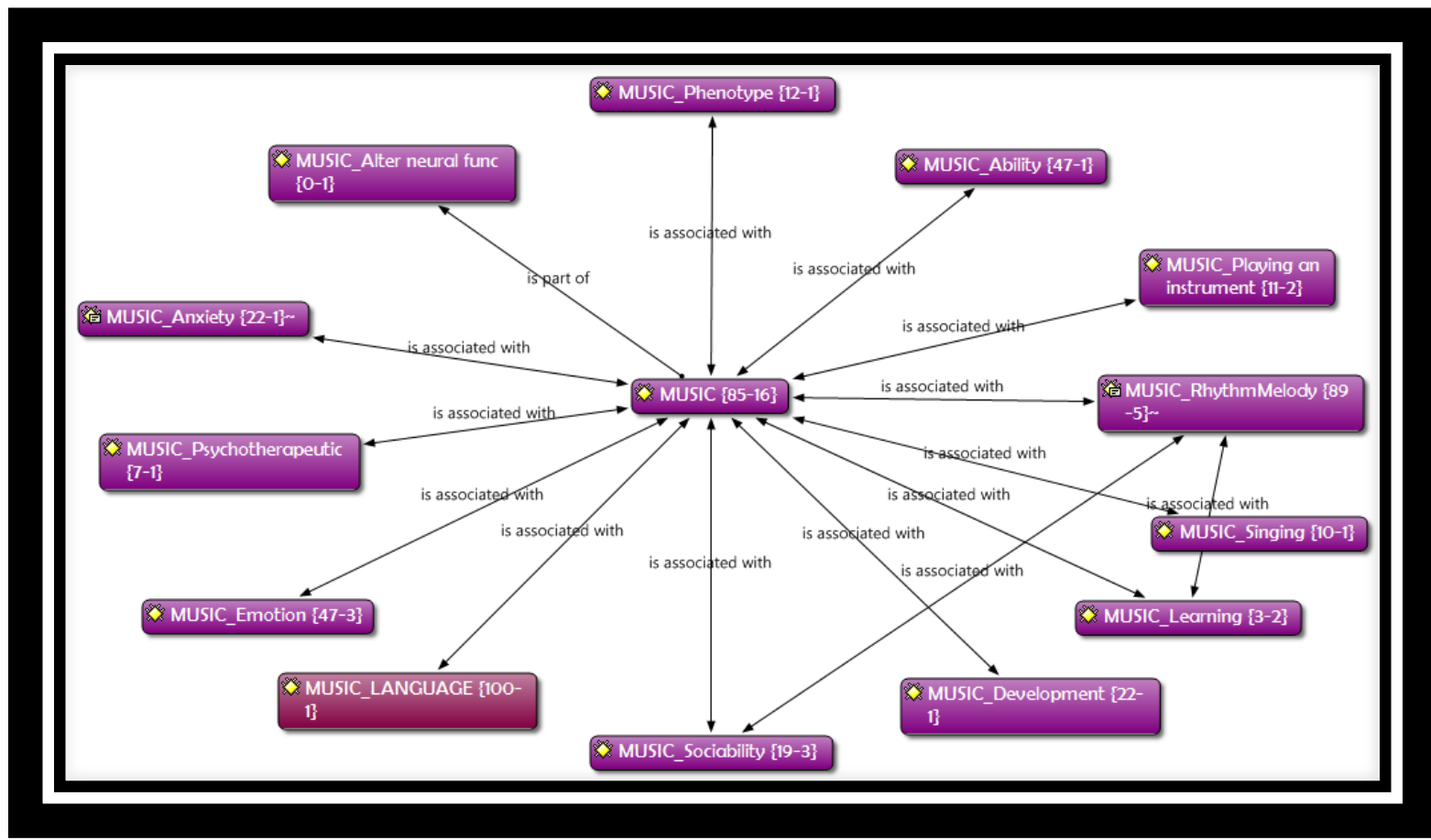

Figure 3: Literature review on music and Williams syndrome also displaying the density of the identified themes and how grounded these themes are in the literature

Studies found that the deletion on chromosome 7, which is a key characteristic of Williams syndrome, is related to the unique auditory perception and musicality associated with the syndrome (Thornton-Wells et al., 2010:42). Thornton-Wells et al. (2010:7) found that people diagnosed with Williams syndrome often exhibit a distinct musical phenotype. Children with the syndrome seem to be drawn to music in an unusual way and will easily spend hours listening to or making music and are more emotionally responsive to music than comparison groups (Dykens et al., 2005:16-18; Salk Institute, 2006:10; Thornton-Wells et al., 2010:8). They appear to have an affinity for music and even present increased musical talent and skill (Dykens et al., 2005:9).

It is important to note that there is as much individual difference in the Williams syndrome population as in a normal one. It would thus be inaccurate to assume that all Williams syndrome individuals are musical. A more accurate statement would be that those diagnosed with the syndrome are more likely to engage in and express a love for music (Levitin \& Bellugi, 2006:3). Williams syndrome children present an extraordinary attentiveness to and grasp of music, together with a deep emotional engagement with music and an above-average 
musical memory (Salk Institute, 2006:8). Research has shown that music can encourage the learning process of those with special needs and this statement seems to hold true for individuals diagnosed with Williams syndrome.

It seems that music is not just a deep and rich part of the lives of Williams syndrome individuals, but that it is ever-present in almost all of their everyday lives. This becomes clear in a study conducted by Levitin and Bellugi (1998:120) where a Williams syndrome child said "Music is my favourite way of thinking". Another child stated that "Music is like soup for the soul, it feels so good." Parents of Williams syndrome individuals provide anecdotes for the fact that music forms a rich part of their children's lives in reporting that their children often gravitate towards musical toys and that their children would easily create musical toys out of different materials (Lense \& Dykens, 2013:35). Williams syndrome and music will now be discussed further in terms of musical phenotype, ability, instruments, rhythm and melody, singing, development and learning, music and sociability, music and language, music and emotion, and music and psychotherapy, anxiety and fear.

\subsection{The musical phenotype of individuals diagnosed with Williams syndrome}

Levitin (2004:236), is of the opinion that there could be a correlation between the social and musical drives displayed by Williams Syndrome individuals and the gene deletion present at conception. Individuals diagnosed with Williams Syndrome seem to be consumed by their affective reactions to music, resulting in them presumably experiencing music more fully than most. Levitin (2005:3) found that several factors such as musical complexity, reproduction, sensitivity, musical theory and achievement, listening, habits, positivity and emotions form part of Williams Syndrome individuals' musical phenotype.

Williams syndrome children reveal a significantly young age for the onset of musical interest (Levitin, 2005:20). They also present an above-average musical memory. The fact that people with Williams syndrome show preserved musical abilities for general music tasks, provide evidence for the independence of music cognition and perception from other cognitive abilities (Levitin \& Bellugi, 1998:58). Levitin and Bellugi (1998:90-122), also argue that Williams syndrome individuals do not seem to have difficulty with response translation for musically based tasks and thus present relatively spared musical ability for both production and perception of musical ideas. This provides further evidence for the idea that there are certain patterns of cognitive dissociations found in individuals diagnosed with the syndrome. It would seem that some of these individuals are musical savants, displaying unusually good abilities in musical tasks and expression, despite their other mental handicaps (Levitin \& Bellugi, 2006:93).

\subsection{Musical abilities}

A study done by Du Four (2008:14), found that Williams syndrome individuals show similar musical abilities to normally developing control groups. The study also revealed that those with Williams syndrome tend to make more 'musical' mistakes during tests than the controls. Some of the Williams syndrome participants even exhibited stronger musical skills than chronological age, sex and dexterity-matched controls. When considering music perception skills, those of individuals with Williams syndrome are equal to normal developing controls. The same is true for their rhythmic production abilities (Levitin, 2005:43). The short-term memory for rhythmic sequences appears to be an area of strength in those with Williams syndrome. Levitin et al. (2003:9), state that it is important to note that Williams syndrome 
individuals are not necessarily very skilful musicians in general, but that their ability to play an instrument is remarkable considering their cognitive and motor impairments. It is true however, that there are cases of people living with the syndrome, presenting remarkable skill on their chosen instruments.

\subsection{Instrumental playing}

People diagnosed with Williams syndrome are more prone to spend time playing instruments, taking music lessons (Dykens et al., 2005:36) and to experience more intense levels of involvement with instruments than the control group (Dykens et al., 2005:27). Levitin and Bellugi (1998:102), report that Williams syndrome individuals execute musical passages, which require a fine degree of control, on the instrument they specialize in (be it clarinet, piano or drums) with less trouble than they have when walking up a flight of stairs or cutting their food. It is true however, that these performances lack a certain degree of technique, but it is compensated for by the degree of subjective musicality the individuals bring to the performance.

\subsection{Rhythm and melody}

Williams syndrome individuals show strengths in tonal and rhythmical tasks (Dykens et al., 2005:11; Salk Institute, 2006:13). When considering the rhythmic and melodic abilities of those with Williams syndrome it would be more appropriate to describe their abilities as strengths in the domain, than areas of preserved functioning (Lense \& Dykens, 2013:7). It would seem that the rhythmic abilities of people with Williams syndrome are stronger than their melodic abilities when rhythmic and melodic production is concerned. However, this disparity does not apply to their perception of rhythm and melody (Levitin, 2005:36).

Levitin (2005:6) conducted a study on the musical abilities of Williams syndrome individuals where they presented abilities which were higher than expected. This was seen when Williams syndrome children were asked to clap rhythmic patterns presented to them. While they did not necessarily clap the exact patterns as required, they did clap patterns that were musically comparable to the phrase given. When referring to melodic reproduction on the other hand, Levitin (2005:7) found that Williams syndrome children performed well when asked to repeat a melodic phrase, but did not perform as well when asked to complete a melodic phrase. When these children's rhythmic and melodic audiation were tested, the Williams syndrome children scored high marks proving that the inequality between rhythmic and melodic production is not influenced by rhythmic and melodic audiation (Levitin, 2005:8).

When engaging in rhythmic tests where Williams syndrome individuals have to clap rhythmic patterns presented to them, they tend to immediately clap back the demonstrations, without missing a beat. They do this so accurately, it seems that their response forms a part of the same rhythmic sequence. Levitin and Bellugi (1998:62), mention that the Williams syndrome subjects who formed part of their study all interpreted the examples as forming part of a larger musical set, assuming an implied time signature and tempo, displaying a clear grasp of metre. Those diagnosed with Williams syndrome also display an astounding ability to track changes in rhythmic pulse. It is interesting to note that these individuals do not seem to have any trouble with rhythmic tasks, even considering their visual-spatial impairment. 
Individuals diagnosed with Williams syndrome further demonstrate remarkable precision when clapping rhythmic patterns presented to them, even though the activity requires coordination and perception of temporal order and rhythmic organisation (Levitin \& Bellugi, 1998:130). Levitin and Bellugi (2006:9) confirmed that Williams syndrome participants performed as well as mentally aged matched controls on rhythmic tasks, but that they showed higher levels of musicality when making mistakes during the tests. When making mistakes, it seemed as if the Williams syndrome participants completed the rhythmic patterns presented to them, thus keeping the musical integrity of the rhythmic piece.

\subsection{Singing}

Dykens et al. (2005:10, 44) state that people with Williams syndrome were perceived as more skilled singers than the control group. Findings reported by the Salk Institute (2006:12) correlate with these findings in the sense that research shows that Williams syndrome individuals possess a great memory for songs. Don et al. (1999:163) conducted a study where they found that Williams syndrome children performed better in verbal than nonverbal tasks, even when engaging in musical tasks. The study lead Don et al. (1999:165) into speculating that the ability Williams syndrome individuals have for the processing of auditory patterns could contribute to their good language and musical abilities. People with Williams syndrome do exceptionally well in tasks where they have to identify certain patterns. This has an impact on their ability to quickly learn a new language and to easily sing songs in different languages (Don et al., 1999:165). It is true, however, that these individuals often sing the correct words with the correct pronunciation without necessarily knowing what they are singing about.

Levitin and Bellugi (1998:104) conducted a study where they found that Williams syndrome individuals would spontaneously compose songs about a wide variety of topics, complete with verse, chorus and rhyming lyrics. These individuals would also easily compose music for their songs, which they often performed using basic chord structures, mostly in the root position.

\subsection{The development and learning of musical skills}

The development of musical abilities could contribute to the development of a wide variety of other skills in the normal population but also in people with special needs. The learning of a musical instrument is a multi-modal experience relying on the student's ability to imitate a teacher's actions, sound, fine- and gross motor movements (Lense \& Dykens, 2013:2). The auditory-motor connections in those diagnosed with Williams syndrome could thus be enhanced with greater exposure to musical activities. According to Lense and Dykens (2013:13), auditory-motor skills are also thought to be the key to good rhythmic perception and production, activities in which Williams syndrome individuals seem to excel.

Music making requires well-developed auditory skills and could assist in the development of visual-spatial abilities in a way that is enjoyable. For optimal development through musical tasks, it is important that one chooses syndrome-specific instruments, taking into consideration the impairments and strengths associated with a specific syndrome (Lense \& Dykens, 2013:22). A study done by Lense and Dykens (2013:25) revealed that musical activities could contribute to the development of visual, auditory, somatosensory and motor skills. This is plausible seeing that the playing of an instrument involves mapping of movement in time and space to sound, while using auditory information to guide the movement. 
It seems then, that instrumental learning might assist visual spatial and motor development in those diagnosed with Williams syndrome in a fun and safe context. Musical activities furthermore enhance abilities pertaining to attention, concentration and memory (Lense \& Dykens, 2013:31). When Williams syndrome individuals participate in musical activities and performance they have the opportunity to develop skills they might otherwise not. These skills, although mentally and logically challenging, include the planning of a repertoire, developing stage presence and stage skills and increasing their consciousness of time and appointment scheduling (Levitin \& Bellugi, 2006:86).

Levitin and Bellugi (2006:80), found anecdotal reports of some success with the teaching of motor action sequences in Williams syndrome individuals, like tying shoes, when these sequences are set to music and taught slowly and gradually. The playing of instruments in ensemble contexts and taking part in group musical activities could provide people with Williams syndrome with opportunities for socialisation.

\subsection{Music and sociability}

Researchers have suggested that there could be a link between gene deletion, sociability and music. This could be attributed to the fact that music played an important role in social bonding and social communication during our evolutionary history. There is thus a speculation that the genes selected for sociability are also those involved in musical behaviour (Levitin, 2005:41).

Williams syndrome individuals are extremely focussed on connecting with people socially. It would seem that they view music as one of the best ways in which to connect with others (Du Four, 2008:32). Their need for socialisation could possibly be one of the reasons they love music. This statement is supported by a study done by Du Four (2008:13), which found that Williams syndrome individuals, due to their extreme sociability, perform better in musical tasks executed by a live person than a recording. Those diagnosed thus present high sociability and high musicality. They also seem to have fewer inhibitions than most people. Therefore, it could be speculated that the high sociability and high musicality displayed by those with Williams syndrome might have an evolutionary basis. The high musicality associated with the syndrome could also be linked to the spared language abilities displayed by individuals diagnosed.

\subsection{Music and language}

Just as Williams syndrome individuals do not scramble words within a sentence or sentences within paragraphs, they do not scramble measures and phrases of a musical piece (Levitin \& Bellugi, 1998:88). There appears to be similarities between the preservation of local motivic elements in language and music. Williams syndrome individuals do not, however, focus on detail in language and music at the expense of the global structure. This then, seems to be another area of dissociation when considering the general cognitive abilities associated with Williams syndrome. According to Levitin and Menon (2003:19), musical and linguistic syntax may share common neural substrates for processing. The musical elements which give meaning are part of the bigger coherent temporal structure, just as it is in language. The findings that Williams syndrome individuals engage with music with extreme emotions also suggest that they are able to focus on the bigger picture where language and music is concerned (Levitin \& Menon, 2003:24). Musical experience is not only a means for 
emotional expression to those diagnosed with Williams syndrome, but also influences their levels of anxiety and fear in everyday life.

\subsection{Music and emotion}

Levitin et al. (2005:12), state that Williams syndrome individuals display heightened emotional responses and attraction to music. In a study done by Dykens et al. (2005:12), they also found that these individuals present high levels of musical expressiveness, similar to normal controls, but that they expressed a greater love of music and a wider range of emotional responsiveness to music than the control group.

The assumption that Williams syndrome sufferers engage with music with extreme emotions seem to be borne out when taking into consideration a study done by Levitin et al. (2004:238), where a little girl began weeping after hearing just a couple of notes at a Mozart concert. Afterwards she commented to her mother: "There are two kinds of Mozart, the kind that hurts and the kind that does not hurt." This could prove to be a key factor in the current study, as it could possibly influence the meaning that these children ascribe to their musical experiences. Don et al. (1999:65), also provide an anecdote for the extreme emotions with which Williams syndrome individuals engage in music by reporting that one child in their study stated that music could not make him happy, because it made him more than happy.

Studies conducted by Levitin et al. (2004:238) and Don et al. (1999:166) show that Williams syndrome individuals engage with music, and sounds in general, with extreme emotion. Levitin et al. (2004:234) also found that Williams syndrome children are more verbally and emotionally expressive when listening to, or engaging with music. It is true, however, that Levitin et al. (2003:8) not only found that these individuals display strong emotional reactions to music, but also to certain classes of noise.

\section{Music and psychotherapy, anxiety and fear}

Music has, since the time of the ancient Greeks, been shown to have an astonishing influence on the mood and well-being of people from different societies and backgrounds (Dykens et al., 2005:3). Music has also been found to provide comfort in times of distress (Levitin \& Bellugi, 2006:78). This holds true for individuals diagnosed with Williams syndrome. The affinity that these individuals show toward music could be contributed to the fact that music offers them the opportunity to control structure, sound and time in ways they cannot do in the rest of their everyday lives (Levitin \& Bellugi, 2006:102). Williams syndrome individuals are well-suited for studies on the effect of music on mood, seeing that individuals diagnosed with the syndrome are prone to problems with anxiety, obsessions, worries, fears and somatic complaints in their daily lives (Dykens et al., 2005:14; Thornton-Wells et al., 2010:6).

Kerchner and Abril (2009:88) state that musical experience plays a role in children's lives, not only in terms of communication, but also in helping children realise their feelings and to create a feeling of belonging in the world. This could in turn lessen feelings of fear and anxiety in children while teaching them to calmly display certain emotions. When people spend time listening to music, they tend to show fewer externalising symptoms for fear and anxiety. The frequency, duration and skill in producing music, together with emotional 
response to music, also have a significant impact on the experience of fear and anxiety in everyday life (Dykens et al., 2005:2).

A study done by Dykens et al. (2005:346), showed that Williams syndrome children were less prone to experience anxiety than other children when listening to or engaging in musical activities. The explanation for this could lie in the fact that Williams syndrome individuals appear to have an affinity for music, show high levels of musical expressiveness and emotional responsiveness to music (Dykens et al., 2005:346-347).

Research reveals that Williams Syndrome individuals experience high levels of anxiety and fear in everyday life. The study done by Dykens et al. (2005:353), proved that the anxiety and stress levels of Williams syndrome children decreased when they started to listen to, or engage with, music. It is true, however, that the study showed heightened levels of fear and anxiety in Williams syndrome individuals when they would say that sad or atonal music makes them happy. This could be a sign of denial or the incapability to recognise the specific emotion or feeling that they want to express for certain music. The individuals who did admit when music made them sad, in contrast, showed lowered levels of fear and anxiety (Dykens et al., 2005:355). It thus seems that music, whether it evokes feelings of sadness of happiness, could contribute to overall wellbeing.

\section{Conclusion}

When studying the existing literature on Williams syndrome there seems to be a dissociation between the musical and language abilities and general cognitive functioning associated with the syndrome. Although Williams syndrome refers to a cognitive phenotype with severe impairments, individuals living with the syndrome tend to excel musically, linguistically and socially.

Music could possibly play a vital role in various areas of development of those with Williams syndrome seeing that musical activities promote motor development, reasoning skills, planning, spatial awareness, social and communicative skills. Music could also provide an opportunity for Williams syndrome individuals to feel that they are good at certain things and it allows them to reach goals that they perhaps otherwise cannot.

Music may have a positive effect on the overall well-being of those diagnosed with Williams syndrome as it promotes a healthy self-esteem, lowers feelings of fear and anxiety and teaches individuals with Williams syndrome about different emotions, allows them to admit to certain emotions and provides a means through which they can express certain emotions appropriately. Finally music is an aspect in the lives of individuals with Williams syndrome which allows them to engage with others socially through a shared interest. It thus becomes clear that music has a larger role to fulfil than assisting in general development. It allows Williams syndrome individuals to foster healthy self-images while promoting a sense of emotional and personal wellbeing.

\section{Reference list}

Bellugi, U., Wang, P. P. \& Jernigan, T. L. 1994. Williams syndrome: an unusual neuropsychological profile. (In Broman, S. \& Grafman, J., ed. Atypical cognitive 
deficits in developmental disorders: implications for brain function. Hillsdale, NJ: Lawrence Erlbaum Associates. p. 1-59).

Bellugi, U., Lichtenberger, L., Jones, W. \& Lai, Z. 2000. The neurocognitive profile of Williams syndrome: a complex pattern of strengths and weaknesses, Journal of cognitive neuroscience, 12:7-29.

Bellugi, U., Järvinen-Parsley, A., Doyle, T. F., Reilly, J., Reiss, A. L \& Korenberg, J. R. 2007. Affect, social behavior and the brain in Williams syndrome, Current directions in psychological science, 16(2):99-104.

Creswell, J. W. 2013. Qualitative inquiry and research design: Choosing among five approaches. Los Angeles: SAGE.

Don, A. J., Schellenberg, E. G. \& Rourke, B. P. 1999. Music and language skills of children with Williams syndrome, Child neuropsychology, 5(3):154-170.

DuFour, E. S. Music performance, Williams syndrome, and Schoenberg's String Trio. San Diego: University of California (Master's degree of Arts).

Dykens, E. M., Rosner, B. A., Ly, T. \& Sagun, J. 2005. Music and anxiety in Williams syndrome: a harmonious of discordant relationship?, American journal on mental retardation, 110(5):346-358.

Gothelf, D., Harber, N., Raveh, E., Apter, A. \& Attias, J. 2006. Hyperacusis in Williams syndrome: characteristics and associated neuroaudiologic abnormalities, Neurology, 66:390-395.

Holinger, D. P., Bellugi, U., <ills, D. L., Korenberg, J. R., Reiss, A. L., Sherman, G. F. \& Galaburda, A. M. 2005. Relative sparing of primary auditory cortex in Williams syndrome, Brain research, 1037:35-42.

Kerchner, J. L. \& Abril, C. R. 2009. Musical experience in our lives, Things we learn and meanings we create. MENC : Maryland.

Lense, M. \& Dykens, E. 2013. Musical learning in children and adults with Williams syndrome, Journal of intellectual disability research, 57(9):850-860.

Levitin, D. J. \& Bellugi, U. 1998. Musical abilities in individuals with Williams syndrome, Music perception: and interdisciplinary journal, 15(4):357-389.

Levitin, D. J. \& Menon, V. 2003. Musical structure is processed in "language" areas of the brain: a possible role for Brodmann Area 47 in temporal coherence, NeuroImage, 20:2142-2152.

Levitin, D. J., Menon, V., Schmitt, J. E., Eliez, S., White, C. D., Glover, G. H., Kadis, J., Korenberg, J. R., Bellugi, U. \& Reiss, A. L. 2003. Neural correlates of auditory perception in Williams syndrome: an fMRI study, NeuroImage, 18:74-82.

Levitin, D. J., Cole, K., Chiles, M., Lai, Z., Lincoln, A. \& Bellugi, U. 2004. Characterizing the musical phenotype in individuals with Williams syndrome, Neuropsychology, 10(4):223-247.

Levitin, D. J. 2005. Musical behavior in a neurogenetic developmental disorder: evidence from Williams syndrome, New York Academy of Sciences, 1060:1-10. 
Levitin, D. J., Cole, K., Lincoln, A. \& Bellugi, U. 2005. Aversion, awareness, and attraction: investigating claims of hyperacusis in the Williams syndrome phenotype, Journal of child psychology and psychiatry, 46:5:514-523.

Levitin, D. J. \& Bellugi, U. 2006. Rhythm, timbre and hyperacusis in Williams-Beuren syndrome (In C. Morris, H. Lenhoff \& P. Wang ed. Williams-Beuren Syndrome: Research and Clinical Perspectives. Baltimore, MD: Johns Hopkins University Press).

Martens, M. A., Reutens, D. C. Wilson, S. J. 2010. Auditory cortical volumes and musical ability in Williams syndrome, Neuropsychologia, 48:2602-2609.

Merriam, S. B. 2009. Qualitative research: A guide to design and implementation. San Francisco: Jossey-Bass.

Pani, J. R., Mervis, C. B. \& Robinson, B. F. 1999. Global spatial organization by individuals with Williams syndrome, Psychological science, 10(5):453-458.

Salk Institute. 2006. Williams syndrome, the brain and music, Science daily 5 October 2006. http://www.sciencedaily.com/releases/2006/10/061003191006.htm Date of access: 5 February 2013.

Thornton-Wells, T. A., Cannistraci, C. J., Anderson, A.W., Kim, C., Epen, M., Gore, J. C., Blake, R. \& Dykens, E. M. 2010. Auditory attraction: activation of visual cortes to music and sound in Williams syndrome, American journal on intellectual and development disabilities, 115(2):172-189. 